\title{
Assessment of knowledge level and behavior about vaccines of mothers applying to the children's hospital
}

\author{
Berkhan Topaktaş ${ }^{1}$, , Şule Özdemir ${ }^{2} \oplus$, Sultan Hasdemir $^{3} \oplus$, Hatice Nilden Arslan $^{3} \oplus$, Özlem Terzi ${ }^{3}$, \\ Cihad Dündar ${ }^{3} \odot$
}

${ }^{1}$ Department of Public Health, Amasya University School of Medicine, Amasya, Turkey; ${ }^{2}$ Public Health Specialist, Provincial Health Directorate, Samsun, Turkey, ${ }^{3}$ Department of Public Health, Ondokuz Mayıs University School of Medicine, Samsun, Turkey

\begin{abstract}
Objectives: The aim of this study is to evaluate the knowledge levels of mothers who applied to a university hospital about childhood vaccinations and the sociodemographic characteristics affecting them.

Methods: The population of the descriptive cross-sectional study consists of mothers who applied to the outpatient clinics of Ondokuz Mayıs University Children's Hospital between February 1 and March 31, 2019. A 32-item questionnaire developed by the researchers was applied to 338 mothers who agreed to participate in the study. Ethics committee and institution permissions were obtained. Data were presented with descriptive statistics.

Results: Ninety-five point three percent of the mothers stated that the vaccine was necessary. While $52.7 \%$ of the individuals stated that they were aware of the existence of self-paid vaccines, it was determined that $84.0 \%$ of the participants did not have self-paid vaccines for their children. Thirty-seven point six of the participants knew that the first vaccine of the newborn was given at birth. Healthcare staffs were among the sources of information for $94.7 \%$ of the mothers who stated that they received information about vaccination.

Conclusions: It was found out that the mothers had information about the vaccine. However, the rate of vaccination other than routine vaccines was low. In order to combat vaccine refusals and prevent misinformation, it is considered to be important to provide information at every opportunity, and especially about paid vaccines, parents should be given more information.

Keywords: Vaccine, knowledge level, mother
\end{abstract}

$\mathrm{T}$ he response caused by the administration of antigen to the body to protect against a microorganism is called "immunization", and the procedure to obtain this response is called "vaccination". Vaccination is one of the most cost-effective health interventions available, saving millions of people from illness, disability and death each year [1]. Despite the current availability of effective and safe vaccines that protect against a range of serious diseases and the develop- ment of many promising new vaccines, these diseases still pose significant threats to developed and developing countries [2]. Routine vaccination services are provided against 13 diseases (diphtheria, pertussis, tetanus, polio, hepatitis B, hepatitis A, H. influenzae type $\mathrm{b}$, tuberculosis, measles, mumps, rubella, chickenpox and pneumococcus) in infants and children within the scope of the "Expanded Immunization Program", which was initiated by the Ministry of Health 
in 2008 in our country. Although it varies by region, it is reported that the childhood vaccination rate in 2019 is between $96-99 \%$ on average [3]. However, the number of fully vaccinated children is below the desired targets. For example, according to Turkey Demographic and Health Survey 2020, it is stated that in $15 \%$ of registered infants who received the first dose of DTaP-IPV-Hib vaccine (Diphtheria, tetanus, acellular pertussis, inactive polio virus, Hemophilus influenza type $b$ ), the third dose was left missing, therefore, full protective resistance cannot be achieved against these five diseases [4].

Among the reasons why children are not fully vaccinated at the appropriate time, it is stated that there are various factors such as the socioeconomic structure of the family, the education level of the parents, the number of children, problems in accessing the health institution, crowded family, parents being young, being a single parent, insufficient or misinformation [5]. In addition, it has been stated that the increasing number of vaccination refusals around the world are due to the lack of sufficient and accurate information about the vaccines by the parents and the speculative news on vaccines in the media [2].

Especially the knowledge, attitude and behavior of mothers about vaccination are important because mothers play an important role in improving the health of children. The practices of mothers to cope with side effects, their negative perception of mild illnesses, negative attitudes towards vaccination, and misconceptions of mothers on vaccination are some of the most important obstacles to childhood vaccination [6]. It is important for mothers to obtain precise and accurate information about vaccines and to develop positive perceptions about vaccines, thus it will contribute to the prevention of many infectious diseases that cause mortality and morbidity in childhood.

In this study, it was aimed to evaluate the knowledge level and influencing sociodemographic characteristics of mothers who applied to a tertiary health institution, which is an important reference hospital in the Black Sea region, about childhood vaccines.

\section{METHODS}

Mothers who applied to Ondokuz Mayıs University
Children's Hospital outpatient clinics between February 1 and March 31, 2019 constituted the population of the study, which is a descriptive cross-sectional type. Considering the average monthly number of patients examined in pediatric outpatient clinics and using the data of a study conducted in our country [7], it was calculated that at least 338 mothers should be reached.

The questionnaire form, which was used as data collection tool in the study, was composed of 32 questions developed by the researchers by reviewing the literature. The survey included 11 questions about the socio-demographic characteristics of the mothers and 21 questions about childhood vaccinations. The answer of the participants who replied the question "What is the first vaccination time of children" in the questionnaire as "At birth" was accepted as correct. After obtaining the permission of the ethics committee (verdict number: 2019/98), the questionnaire application was initiated by the researchers using the face to face interview method. Beforehand, explanatory information was given to the mothers about the study and verbal consent was obtained from all mothers who agreed to participate.

\section{Statistical Analysis}

After the data were encoded, they were transferred to the SPSS (Version 22 for Windows, SPSS Inc, Chicago, IL, USA) program and analyzed. Continuous variables were expressed as mean \pm standard deviation and discrete variables as numbers and percentages $(\%)$. Analysis of data was made using Pearson chisquare and Fisher's exact test. The statistical significance level for all tests was accepted as $p<0.05$.

\section{RESULTS}

The mean age of 338 mothers was $33.6 \pm 6.8$ years, and $33.4 \%$ were primary school graduates. It was determined that $79.6 \%$ of the participants did not have a job, $46.2 \%$ had two children, and the household income of $43.2 \%$ was between 2,001 and $3,000 \mathrm{TL}$ (Turkish Lira) (Table 1).

Ninety-five point three percent of the mothers stated that the vaccine was necessary, while $4.7 \%$ stated that it was not. When Table 2, in which the ques- 
Table 1. Sociodemographic characteristics of the mothers $(n=338)$

\begin{tabular}{|ccc}
\hline Characteristics & $\mathbf{n}$ & $\mathbf{\%}$ \\
\hline Age group (years) & & \\
\hline $18-34$ & 199 & 58.9 \\
\hline $35-64$ & 139 & 41.1 \\
\hline Education status & & \\
\hline Primary education & 113 & 33.4 \\
\hline Secondary education & 65 & 19.2 \\
\hline High school & 87 & 25.7 \\
\hline University & 73 & 21.6 \\
\hline Working status & & \\
\hline Not working & 269 & 79.6 \\
\hline Officer & 42 & 12.4 \\
\hline Worker & 10 & 3.0 \\
\hline Other & 17 & 5.0 \\
\hline Total household income (TL) & & \\
\hline $0-2,000$ & 83 & 24.6 \\
\hline $2,001-3,000$ & 146 & 43.2 \\
\hline $3,001-4,500$ & 41 & 12.1 \\
\hline Above 4,500 & 68 & 20.1 \\
\hline Number of children & & \\
\hline 1 & 80 & 23.7 \\
\hline 2 & 156 & 46.2 \\
\hline 3 & 75 & 22.2 \\
\hline 4 and above & 27 & 7.9 \\
\hline
\end{tabular}

tions and answers are presented measuring the knowledge level of the participants, is examined, $90.1 \%$ of the people who considered the vaccine necessary answered the question "Why do you think vaccination is necessary" as "The vaccine protects from infectious diseases". The answer of $73.3 \%$ of the mothers to the question "What would be the harm if the vaccine is not given" was "Infectious diseases increase". While the answer to the question about whether vaccines have any side effects was "yes" with a rate of $85.5 \%$, the most commonly said side effect was "fever" (90.6\%). Thirty-seven point six percent of the participants stated that the first vaccine of the newborn was given at birth, $95.6 \%$ of the participants stated that the vaccines were administered in family health centers and $74.5 \%$ of the participants said that the vaccines were administered by nurses. Fifty-two point seven percent of the individuals stated that they were aware of the existence of self-paid vaccines and $70.3 \%$ of them specified that vaccines could be delayed in the presence of disease.

According to the statements of the participants, the number of children who developed side effects after any vaccination was found to be $150(44.4 \%)$, and the number of children who had the related disease despite vaccination was $27(8.0 \%)$. Healthcare staff were among the sources of information for $305(94.7 \%)$ of $322(95.3 \%)$ mothers who stated that they had received information about vaccination. Other sources of information were listed as internet (5.0\%), neighbors and friends $(1.9 \%)$ and television, radio, and newspaper $(1.6 \%)$. It was determined that 284 of the participants $(84.0 \%)$ did not have self-paid vaccines for their children. The most common reasons for this were the lack of knowledge about self-paid vaccines $(63.4 \%)$ and not thinking that it was necessary $(38.4 \%)$.

In Tables 3 and 4, the distribution of knowledge levels, attitudes and behaviors of the mothers on vaccination according to their sociodemographic characteristics are presented. Accordingly, those between the ages of 35-64 were more aware of the existence of self-paid vaccines and the frequency of self-paid vaccination was higher than those in the 18-34 age group ( $p=0.009$ and $p<0.001$, respectively). On the other hand, mothers between the ages of 18-34 knew the time of first vaccination more accurately $(p=0.005)$. Participants with high school education and above gave more accurate answers about the availability of self-paid vaccines $(p<0.001)$, time of first vaccination $(p<0.001)$ and delay of vaccines $(p=0.017)$. The frequency of getting self-paid vaccination $(p<0.001)$ and getting information about vaccination $(p=0.004)$ was also higher in this group. It was determined that working mothers had more information about the side effects of vaccines $(p=0.036)$, existence of self-paid vaccines $(p<0.001)$ and time of first vaccination $(p=$ $0.011)$ and got more self-paid vaccinations for their children $(p<0.001)$. Individuals with a total household income above 3,000 TL were more successful in self-paid vaccination $(p<0.001)$ and vaccination postponement questions $(p=0.012)$; it was found out that they got more self-paid vaccines $(p=0.003)$, got more information about vaccination $(p=0.023)$, and bene- 
Table 2. Distribution of mothers' responses to questions about vaccines

\begin{tabular}{|c|c|c|c|c|c|}
\hline Questions & $\mathbf{n}$ & $\% \dagger$ & Questions & $\mathbf{n}$ & $\% \dagger$ \\
\hline Are there self-paid vaccines? $(n=336)$ & & & $\begin{array}{l}\text { Are there any side effects of } \\
\text { vaccines? }(n=338)\end{array}$ & & \\
\hline Yes & 177 & 52.7 & Yes & 299 & 88.5 \\
\hline No & 159 & 47.3 & No & 39 & 11.5 \\
\hline $\begin{array}{l}\text { What will be the harm if the vaccine is } \\
\text { not given?* }(n=322)\end{array}$ & & & $\begin{array}{l}\text { What are the side effects of } \\
\text { vaccines?* }(\mathrm{n}=299)\end{array}$ & & \\
\hline Infectious diseases increase & 236 & 73.3 & Fever & 271 & 90.6 \\
\hline The disease is severely cured & 50 & 15.5 & Rash & 103 & 34.4 \\
\hline Disabilities - fatal risks occur & 34 & 10.6 & Allergy & 91 & 30.4 \\
\hline I don't know & 19 & 5.9 & Gets sick & 6 & 2.0 \\
\hline Other & 11 & 3.4 & Other & 33 & 11.0 \\
\hline Who applies the vaccine?* $(n=333)$ & & & $\begin{array}{l}\text { Where are vaccines } \\
\text { administered? }{ }^{*}(n=338)\end{array}$ & & \\
\hline Nurse & 248 & 74.5 & Family Health Center & 323 & 95.6 \\
\hline Midwife & 151 & 45.3 & Hospital & 72 & 21.3 \\
\hline Physician & 33 & 9.9 & Maternity and Child Health Center & 4 & 1.2 \\
\hline $\begin{array}{l}\text { Why are vaccinations necessary?* }(n= \\
\text { 322) }\end{array}$ & & & $\begin{array}{l}\text { When is the first vaccination of } \\
\text { newborn? }(n=338)\end{array}$ & & \\
\hline Protect against infectious diseases & 290 & 90.1 & At birth & 127 & 37.6 \\
\hline The disease is mildly cured & 10 & 3.1 & One month old & 82 & 24.3 \\
\hline Other & 24 & 7.5 & One week old & 38 & 11.2 \\
\hline I don't know & 5 & 1.6 & Two weeks old & 3 & 0.9 \\
\hline Can vaccinations be delayed? $(n=333)$ & & & I don't know & 88 & 26.0 \\
\hline When gets sick & 234 & 70.3 & & & \\
\hline Cannot be delayed & 18 & 5.4 & & & \\
\hline I don't know & 81 & 24.3 & & & \\
\hline
\end{tabular}

*Multiple choices, $\uparrow$ Calculated on valid respondents

fited more from healthcare staff as a source of information $(p=0.016)$.

\section{DISCUSSION}

The majority of mothers in the study stated that vaccination was necessary. In a study conducted in Zonguldak, all mothers and 98\% in Hatay stated that they considered vaccination necessary $[8,9]$. In a study in Italy, $86.2 \%$ of the parents found it necessary to apply vaccines even if a healthy lifestyle was followed and natural treatments were used [10]. Considering that the anti-vaccine tendency has increased in the world and in our country especially in recent years [11], it is a positive finding that vaccines are considered necessary by the majority of the mothers included in our study, regardless of sociodemographic characteristics such as education level, age group, employment status or household income.

Local side effects such as pain, swelling and erythema at the injection site, mostly mild and temporary, and systemic side effects such as fever and rash may occur after vaccination applications. Much less often than these side effects, there is a risk of developing anaphylaxis to the vaccine or its components, with about one in a million doses [12]. In order not to take a negative attitude about vaccination, we think it is im- 
Table 3. Distribution of mothers who gave correct answers according to their sociodemographic characteristics

\begin{tabular}{|c|c|c|c|c|c|c|}
\hline \multirow[t]{2}{*}{ Characteristics } & \multicolumn{6}{|c|}{ Correct Answers to Questions (\%) } \\
\hline & $\begin{array}{l}\text { Are there any } \\
\text { side effects of } \\
\text { vaccines? }\end{array}$ & $\begin{array}{c}\text { Are there any } \\
\text { self-paid } \\
\text { vaccines? }\end{array}$ & $\begin{array}{l}\text { When is the } \\
\text { first vaccine } \\
\text { given? }\end{array}$ & $\begin{array}{c}\text { Can } \\
\text { vaccination be } \\
\text { postponed? }\end{array}$ & $\mathbf{n}$ & $\%$ \\
\hline \multicolumn{7}{|l|}{ Age group (years) } \\
\hline $18-34$ & 85.9 & 46.7 & 43.7 & 69.1 & 199 & 58.9 \\
\hline $35-64$ & 92.1 & 61.2 & 28.8 & 71.9 & 139 & 41.1 \\
\hline$p$ value & 0.081 & 0.009 & 0.005 & 0.572 & & \\
\hline \multicolumn{7}{|l|}{ Education status } \\
\hline $\begin{array}{l}\text { Secondary school } \\
\text { and below }\end{array}$ & 87.6 & 36.4 & 25.3 & 64.6 & 178 & 52.7 \\
\hline $\begin{array}{l}\text { High school and } \\
\text { above }\end{array}$ & 89.4 & 70.6 & 51.3 & 76.6 & 160 & 47.3 \\
\hline$p$ value & 0.618 & $<0.001$ & $<0.001$ & 0.017 & & \\
\hline \multicolumn{7}{|l|}{ Working status } \\
\hline Not working & 86.6 & 46.3 & 34.2 & 68.8 & 269 & 79.6 \\
\hline Working & 95.7 & 77.9 & 50.7 & 76.1 & 69 & 20.4 \\
\hline$p$ value & 0.036 & $<0.001$ & 0.011 & 0.241 & & \\
\hline \multicolumn{7}{|l|}{$\begin{array}{l}\text { Total household income } \\
\text { (TL) }\end{array}$} \\
\hline Below 3,000 & 87.8 & 41.2 & 34.5 & 65.9 & 229 & 67.8 \\
\hline 3,000 and above & 89.9 & 76.9 & 44.0 & 79.4 & 109 & 32.2 \\
\hline$p$ value & 0.566 & $<0.001$ & 0.091 & 0.012 & & \\
\hline \multicolumn{7}{|l|}{ Number of children } \\
\hline 1 & 95.0 & 55.0 & 40.0 & 66.7 & 80 & 23.7 \\
\hline 2 & 86.5 & 57.8 & 41.0 & 71.4 & 156 & 46.2 \\
\hline 3 and above & 86.3 & 43.1 & 30.4 & 71.3 & 102 & 30.2 \\
\hline$p$ value & 0.111 & 0.064 & 0.198 & 0.728 & & \\
\hline
\end{tabular}

portant for parents to know these symptoms and to be aware that these side effects are expected and temporary. Eighty-eight point five percent of the mothers in the study stated that vaccines had side effects, and this rate was found to be $73.7 \%$ in another study [9]. In studies involving parents and adults, the rate of those who stated that vaccines had side effects was $53.6 \%$ and $67.7 \%$, respectively $[7,13]$. In our study, it was determined that working mothers knew the side effects of vaccines with a higher frequency. Similarly, correct answers to other questions of knowledge were received with high frequency in this group. This may be due to working mothers' communication with mothers who have similar experiences in the working environment, or different factors such as education and economic levels. As a limitation of the study, working mothers constituted approximately one-fifth of the participants in this study. However, the participation of working mothers in similar studies was also low [7, 9]. Different study designs in which the two groups show a similar distribution are needed to determine the factors affecting knowledge levels of working and non-working mothers.

The answers given to the question of which side effects can be seen in vaccines, although the order varies, were found to be generally similar to those in 
Table 4. Distribution of mothers' attitudes and behaviors towards vaccination according to sociodemographic characteristics

\begin{tabular}{|c|c|c|c|c|c|c|}
\hline \multirow[t]{2}{*}{ Characteristics } & \multicolumn{6}{|c|}{ Questions } \\
\hline & $\begin{array}{c}\text { Is } \\
\text { vaccination } \\
\text { necessary? }\end{array}$ & $\begin{array}{c}\text { Have you got } \\
\text { a self-paid } \\
\text { vaccine? }\end{array}$ & $\begin{array}{c}\text { Do you obtain } \\
\text { information } \\
\text { about } \\
\text { vaccination? }\end{array}$ & $\begin{array}{l}\text { Who is your } \\
\text { source of } \\
\text { information on } \\
\text { vaccination? }\end{array}$ & $\mathbf{n}$ & $\%$ \\
\hline & Yes $(\%)$ & Yes $(\%)$ & Yes $(\%)$ & $\begin{array}{c}\text { Healthcare staff } \\
(\%)\end{array}$ & & \\
\hline \multicolumn{7}{|l|}{ Age group (years) } \\
\hline $18-34$ & 94.5 & 8.7 & 95.0 & 90.4 & 199 & 58.9 \\
\hline $35-64$ & 96.4 & 23.9 & 95.7 & 91.4 & 139 & 41.1 \\
\hline$p$ value & 0.411 & $<0.001$ & 0.763 & 0.752 & & \\
\hline \multicolumn{7}{|l|}{ Education status } \\
\hline $\begin{array}{l}\text { Secondary } \\
\text { school and below }\end{array}$ & 95.5 & 8.6 & 92.1 & 89.2 & 178 & 52.7 \\
\hline $\begin{array}{l}\text { High school } \\
\text { and above }\end{array}$ & 95.0 & 22.0 & 98.8 & 92.5 & 160 & 47.3 \\
\hline$p$ value & 0.827 & 0.001 & 0.004 & 0.297 & & \\
\hline \multicolumn{7}{|l|}{ Working status } \\
\hline Not working & 95.2 & 11.2 & 95.2 & 90.7 & 269 & 79.6 \\
\hline Working & 95.7 & 29.9 & 95.7 & 91.2 & 69 & 20.4 \\
\hline$p$ value & $1.000^{*}$ & $<0.001$ & $1.000^{*}$ & 0.898 & & \\
\hline \multicolumn{7}{|l|}{$\begin{array}{l}\text { Total household income } \\
\text { (TL) }\end{array}$} \\
\hline Below 3,000 & 96.5 & 11.0 & 93.4 & 88.2 & 229 & 67.8 \\
\hline $\begin{array}{l}3,000 \text { and } \\
\text { above }\end{array}$ & 92.7 & 23.4 & 99.1 & 96.3 & 109 & 32.2 \\
\hline$p$ value & 0.120 & 0.003 & 0.023 & 0.016 & & \\
\hline \multicolumn{7}{|l|}{ Number of children } \\
\hline 1 & 95.0 & 16.3 & 96.3 & 92.5 & 80 & 23.7 \\
\hline 2 & 96.2 & 17.6 & 94.9 & 89.0 & 156 & 46.2 \\
\hline 3 and above & 94.1 & 9.9 & 95.1 & 92.2 & 102 & 30.2 \\
\hline$p$ value & 0.747 & 0.223 & 0.891 & 0.571 & & \\
\hline
\end{tabular}

*Fisher's exact test

other studies [7-9, 13]. It was determined that 44.4\% of the children of the participants developed side effects after vaccination. This was higher than the two domestic studies, in which the related rates were $13.3 \%$ and $15.0 \%[8,14]$. In a study carried out in Egypt, this rate was found to be much higher with $94.4 \%$, and most of these side effects were fever [15]. The reason for these differences may be related to the difference in the options presented in the closed-ended questions, the memory factor or the application of the vaccines at the country level and the difference in the vaccines administered.

In studies involving mothers and parents across the country, the rate of awareness of self-paid vaccines outside the Expanded Immunization Program varies between $27.8 \%$ and $63.3 \%$ [7-9, 16]. In our study, this 
rate was found to be $52.7 \%$ and the rate of the participants who had their children vaccinated at least once for a fee was $16.0 \%$. Similarly, the frequency of selfpaid vaccination was found as low as $9.7 \%$ and $15.6 \%$ in other studies $[7,9]$. In one of those studies, similar to the this study, the most common reason was not having knowledge about self-paid vaccines [9]. The higher frequency of self-paid vaccination among mothers in the 35-64 age group, with higher education and income levels, and those working in a job is generally compatible with the literature $[7,9,16]$. These findings show that awareness about paid vaccines, income and education level play an important role in the administration of these vaccines.

Hepatitis B vaccine, the first vaccine given to babies, should be administered within the first 72 hours after birth, preferably within the first 24 hours [17]. While the rate of knowing that the first vaccine was given at birth was found to be $65.4 \%$ and $92.2 \%$ in studies conducted in our country $[8,9]$, this rate ranged between $68.5 \%$ and $97.1 \%$ in studies abroad [18-20]. The rate of knowing the time of first vaccination was found to be $37.6 \%$ in this study, and it was quite low compared to the literature. Although individuals in the 35-64 age group, who are not working and have a secondary school or less education level, give correct answers to this question at a lower rate, it is an issue that should be emphasized that almost half of the mothers with high school and above education level could not give the correct answer.

In conditions such as severe illness or high fever, it is preferable to postpone vaccinations until recovery [21]. Seventy point three percent of the mothers knew that vaccines could be delayed when the disease develops. In this respect, a similar result was obtained in a study conducted on parents in Istanbul, and 71.6\% of the participants stated that vaccines could be delayed when fever or disease occurred [22]. The point that should not be overlooked in this regard is that diseases such as mild upper respiratory tract infections do not prevent vaccination, and the decision to postpone in cases of severe illness and high fever should be made by the physician [21]. In the questions posed in our study, not making a distinction between disease and severe disease can be considered as a limitation.

Ninety-five point three of the participants stated that they received information about vaccination. In studies involving mothers or parents in our country, the rate of those who declared that they received information varies between $58.3 \%$ and $88.6 \%$, and similar to our study, it is seen that healthcare staff are the most benefited as a source of information [7-9, 14]. There are different findings about the source of information abroad. For example, in studies involving pregnant women, it was determined that word-of-mouth information was obtained most frequently in Italy, and more frequently from family or friends in China [23, 24]. In Ethiopia, it was observed that mothers or caregivers received the most information about vaccination from healthcare workers [18]. It is of utmost importance to obtain accurate information in order to reduce the increasing number of vaccine rejection and to eliminate false hesitations about vaccination. For this purpose, we think that the primary source of information should be health professionals. As a matter of fact, even if information is obtained from different sources, it has been shown that physicians are trusted the most in this regard [24] and that giving positive opinions by physicians increases the rate of vaccination [25].

Among the mothers, those with high school or higher education, those working in a job, and those with higher income were more knowledgeable in most of the information questions. This situation is similar in many studies carried out in our country and abroad, and it is seen that people with high education or income levels are more conscious about vaccination [19, $20,23,26-28]$. Assuming that people with a high level of education are more involved in business life and have higher income, we think that the main determinant variable in this issue is the level of education. We found that the number of children did not affect the level of knowledge or attitudes and behaviors about vaccination. There are different findings on this subject in similar studies. For example, as the number of children increased in the parents who applied to the pediatric health and diseases outpatient clinic in İzmir, there was a decrease in the rate of parents who know about self-paid vaccines and have these vaccinations for their children [7]. In a study conducted in Lebanon, as the number of children increased, it was seen that the knowledge, attitude and behavior scores of the parents about vaccination decreased [26]. It was determined that the number of children did not affect the knowledge level of vaccination in a study carried out in Kars, similar to our study [27]. 


\section{Limitations}

This study has several limitations. Since the sample of the study consists of mothers who applied to the hospital, the results can be generalized to the population they belong to. Post-vaccination side effects and disease development is a finding based on mothers' statements. In the question about vaccination postponement, no distinction was made between illness and severe illness.

\section{CONCLUSION}

As a result, it was found out that the majority of the mothers in this study considered the vaccine necessary, had information about the side effects of vaccines, but did not have enough information about the time of the first vaccination, and although almost half of the participants were aware of the existence of paid vaccine, a small portion of them had paid vaccines for their children. It turned out that those with higher education and income levels and those who work were generally more knowledgeable about vaccination, almost all mothers were informed about vaccination in some way, and healthcare staff ranked first as the source of information. In order to prevent vaccination refusals and misinformation, it is thought that the continuity of first-hand information provided by healthcare professionals is of great importance and the information needs of parents should be met, especially about paid vaccines.

\section{Authors' Contribution}

Study Conception: BT, ŞÖ, SH, HNA, ÖT, CD; Study Design: BT, ŞÖ, SH, HNA, ÖT, CD; Supervision: BT, ŞÖ, SH, HNA, ÖT, CD; Funding: CD; Materials: HNA; Data Collection and/or Processing: ŞÖ; Statistical Analysis and/or Data Interpretation: $\mathrm{SH}$; Literature Review: BT; Manuscript Preparation: ÖT and Critical Review: BT, ŞÖ, SH, HNA, ÖT, CD.

\section{Conflict of interest}

The authors disclosed no conflict of interest during the preparation or publication of this manuscript.

\section{Financing}

The authors disclosed that they did not receive any grant during conduction or writing of this study.

\section{REFERENCES}

1. Öztek Z. Bulaşıcı hastalıkların kontrolü. In: Öztek Z ed. Halk Sağlığı Kuramlar ve Uygulamalar. Ankara: Bireklam Arısı; 2020:324-25.

2. Baker LM, Wilson FL, Nordstrom CK, Legwand C. Mothers' knowledge and information needs relating to childhood immunizations. Issues Compr Pediatr Nurs 2007;30:39-53.

3. Ministry of Health. Health Statistics Yearbook 2019 News Bulletin. 2020:2.

4. Eskiocak M. Türkiye'de bağışıklama hizmetlerinin durumu ve bağışıklamada eşitsizlikler. In: Üner S, Okyay P, eds. Turkey Demographic and Health Survey. Ankara:Hipokrat Yayınevi; 2020:494-95.

5. Yiğit T, Oktay BÖ, Özdemir CN, Moustafa Pasa S. [Anti-vaccination and it's intellectual appearance]. J Soc Humanit Sci Res 2020;53:1244-61. [Article in Turkish]

6. Hegazy SM, Omar AM, Alshiekh I. A conceptual framework for construction and validation of an educational booklet for treating mothers misconceptions on vaccination. Saudi J Nurs Health Care 2020;3:55-67.

7. Üzüm Ö, Eliaçık K, Hortu Örsdemir H, Karadağ Öncel E. Factors affecting the immunization approaches of caregivers: an example of a teaching and research hospital. J Pediatr Inf 2019;13:e144-9.

8. Kürtüncü M, Alkan I, Bahadır Ö, Arslan N. [The knowledge levels of mothers about the vaccination status of children living in a rural area of Zonguldak]. Electron J Vocat Coll 2017;7:8-17. [Article in Turkish]

9. Ç1klar S, Döner Güner P. [Knowledge, behavior and attitude of mother's about childhood immunization and reasons of vaccination rejection and hesitancy: a study of mixed methodology]. Ankara Med J 2020;20:180-95. [Article in Turkish]

10. Giambi C, Faibani M, D'Ancona F, Ferrara L, Fiacchini D, Gallo T, et al. Parental vaccine hesitancy in Italy-results from a national survey. Vaccine 2018;36:779-87.

11. Gür E. Vaccine hesitancy - vaccine refusal. Turk Pediatri Ars 2019;54:1-2.

12. Spencer JP, Pawlowski RHT, Thomas S. Vaccine adverse events: separating myth from reality. Am Fam Physician 2017;95:786-94.

13. Bolatkale MK, Kutlu R, Eryılmaz MA. [The adult immunization knowledges and vaccination status of individuals who applied to family medicine polyclinic]. Konuralp Tip Dergisi 2019;11:362-68. [Article in Turkish]

14. Odabaş N, Kuzlu Ayyıldız T. [Evaluation of knowledge and practice of parents about childhood vaccines]. Batı Karadeniz Tıp Dergisi 2020;4:7-11. [Article in Turkish]

15. Ramadan HA, Soliman SM, Abd El-Kader RG. Knowledge, attitude and practice of mothers toward children's obligatory vaccination. J Nurs Health Sci 2016;5:22-8.

16. Gençer MZ, Alıcıoğlu F, Arıca S, Arıca V. [Socio-demographic characteristics of parents with children between 24-72 months of age and their knowledge and attitudes about self-paid vaccines: comparison of east vs. west]. Konuralp Tip Dergisi 2015;7:141-5. [Article in Turkish]

17. Ministry of Health. Hepatit B Hastalığı. Available at: 
https://asi.saglik.gov.tr/liste/4-hepatit-bhastal $\% \mathrm{C} 4 \% \mathrm{~B} 1 \% \mathrm{C} 4 \% 9 \mathrm{~F} \% \mathrm{C} 4 \% \mathrm{~B} 1$-nedir.html. Accessed January 30, 2021.

18. Yismaw AE, Assimamaw NT, Bayu NH, Mekonen SS. Incomplete childhood vaccination and associated factors among children aged 12-23 months in Gondar city administration, Northwest, Ethiopia 2018. BMC Res Notes 2019;12:1-7.

19. Mugada V, Chandrabhotla S, Kaja DS, Machara SGK. Knowledge towards childhood immunization among mothers \& reasons for incomplete immunization. J App Pharm Sci 2017;7:157-61.

20. Balbir Singh HK, Badgujar VB, Yahaya RS, Rahman SA, Sami FM, Badgujar S, et al. Assessment of knowledge and attitude among postnatal mothers towards childhood vaccination in Malaysia. Hum Vaccin Immunother 2019;15:2544-51.

21. Centers for Disease Control and Prevention. Vaccines When Your Child Is Sick. Available at: h t t p s :// w w w. cd c.gov/vac cines/h c p/patient ed/conversations/downloads/fs-child-sick.pdf. Accessed February $1,2021$.

22. Özdemir İN. Knowledge, attitudes and behaviour of the parents against childhood vaccines. [Master thesis]. Marmara University Institute of Health Sciences;2017:36-38.

23. Rosso A, Massimi A, De Vito C, Adamo G, Baccolini V,
Marzuillo C, et al. Knowledge and attitudes on pediatric vaccinations and intention to vaccinate in a sample of pregnant women from the City of Rome. Vaccine 2019;37:1954-63.

24. Hu Y, Chen Y, Wang Y, Song Q, Li Q. Prenatal vaccination education intervention improves both the mothers' knowledge and children's vaccination coverage: evidence from randomized controlled trial from eastern China. Hum Vaccin Immunother 2017; 13:1477-84.

25. Facciolà A, Visalli G, Orlando A, Bertuccio MP, Spataro P, Squeri R, et al. Vaccine hesitancy: an overview on parents' opinions about vaccination and possible reasons of vaccine refusal. J Public Health Res 2019;8:13-18.

26. Matta P, El Mouallem R, Akel M, Hallit S, Khalife MCF. Parents' knowledge, attitude and practice towards children's vaccination in Lebanon: role of the parent-physician communication. BMC Public Health 2020;20:1-9.

27. Evran M, Bozkurt HB. [Knowledge status and affecting factors about the current childhood vaccines of mothers of children applying to state and university hospital pediatric clinics in Kars]. Kafkas J Med Sci 2020;10:173-9. [Article in Turkish]

28. Çam C, Ünsal A, Arslantaş D, Kılınç A, Öztürk Emiral G. [Evaluation of immunization knowledge sufficiency levels, attitudes and behaviors and health literacy levels of adults]. Osmangazi Tip Dergisi 2021;43:7-19. [Article in Turkish] 